HUOM! Tämä on alkuperäisen artikkelin rinnakkaistallenne. Rinnakkaistallenne saattaa erota alkuperäisestä sivutukseltaan ja painoasultaan.

Käytä viittauksessa alkuperäistä lähdettä:

R. Kauppinen, K. Silpiö, J. Hyrkäs (2021) A HYBRID APPROACH TO REQUIREMENTS ANALYSIS ON AN EDUCATION ANALYTICS SYSTEM, ICERI2021 Proceedings, pp. 672-681.

https://doi.org/10.21125/iceri.2021.0217

PLEASE NOTE! This in an electronic self-archived version of the original article. This reprint may differ from the original in pagination and typographic detail.

Please cite the original version:

R. Kauppinen, K. Silpiö, J. Hyrkäs (2021) A HYBRID APPROACH TO REQUIREMENTS ANALYSIS ON AN EDUCATION ANALYTICS SYSTEM, ICERI2021 Proceedings, pp. 672-681.

https://doi.org/10.21125/iceri.2021.0217

(C) 2021 IATED. All rights reserved. 


\title{
A HYBRID APPROACH TO REQUIREMENTS ANALYSIS ON AN EDUCATION ANALYTICS SYSTEM
}

\author{
R. Kauppinen, K. Silpiö, J. Hyrkäs \\ Haaga-Helia University of Applied Sciences (FINLAND)
}

\begin{abstract}
Requirements analysis is an essential part of system development. Traditionally, a plan-driven approach has been used in requirements analysis. However, change-driven approaches have gained popularity since agile development has become more widespread in system development. While both approaches are well known, they require an application based on the case at hand, and the results of their application vary in practice, meaning that requirements analysis is a non-trivial task.

In recent years, analytics have been in focus in the education domain. The majority of the work has been on study and learning analytics where the actions and the results come from students. The data is collected in the learning environment and in the study management systems, such as the study registry, and analyzed to track a student's progress. Based on this, for example, the need for the intervention by a teacher in an individual student can be identified. In addition to the study and the learning analytics, other areas of analytics, such as environmental, biometric, and behavioral have been identified.
\end{abstract}

However, there are still additional, related areas of analytics applicable in education. For example, while current analytics focus on the actions of the student, they focus less on the actions of the teacher and the related workflow. Also, an important viewpoint is the possibility of guidance by using the information gained via analytics. Often, this is thought to be the guidance of an academic advisor to a student, but it can also be the guidance of a teacher, or self-guidance of the student, made possible by on-time accurate information gained from analytics.

In order to benefit from analytics, there is a need for an education analytics system to have the data available, and supporting the needs and requirements of the relevant stakeholders. Since these kinds of systems are not that common currently, many educational organizations are building or planning to build them. This should entail doing a feasible requirements analysis of the education analytics system.

In this paper, we present a case study of an ongoing project in Haaga-Helia University of Applied Sciences, aimed at building an education analytics system for the relevant stakeholders in the organization. We completed the initial requirements analysis in the project and, based on the results and knowledge gained, we present our approach to requirements analysis on an education analytics system. We used a hybrid of a plan-driven and change-driven approach, and we discuss the reasoning behind this decision. We describe the approach, both its plan-driven and change-driven components, and based on our work and observations on the case so far, we discuss the lessons learned.

Keywords: requirements analysis, education analytics, system development, case study, lessons learned.

\section{INTRODUCTION}

Requirements analysis is an essential part of system development. As such, it is a phase or a part of the system development life cycle and digitalization models [1]-[3]. Traditionally, plan-driven approaches were used in requirements analysis, but change-driven approaches have gained popularity singe agile development has become more mainstream [4], [5]. A hybrid approach is also possible [6]. While the approaches are well known, they require to be applied based on the case at hand [7]; and the results of their application vary in practice, meaning that requirements analysis is a non-trivial task [4].

In recent years, analytics have been in focus in the education domain [8]-[14]. The majority of the work has been on study and learning analytics, where the actions and the results come from students [8][10]. The data is collected in the learning environment and in the study management systems, such as the study registry [11], [12]. The data is analyzed to track the student's progress. Based on this, for example, the need for the intervention by the teacher in an individual student can be identified. In addition to the study and the learning analytics, other areas of analytics, such as environmental, biometric, and behavioral have been identified [13], [14]. 
However, there are still additional related areas of analytics applicable in education. For example, while current analytics focus on the actions of the student, they focus less on the actions of the teacher and the related workflow [14]. Also, an important viewpoint is the possibility of guidance by using the information gained via analytics. Often, this is thought to be the guidance of an academic advisor to a student, but it can also be the guidance of a teacher, or self-guidance of the student, made possible by on-time accurate information gained from analytics.

In order to benefit from analytics, there is a need for an education analytics system [9], [11], [14], to have the analytics data available, and supporting the needs and requirements of the relevant stakeholders. Since building such a system is system development, it should entail doing a feasible requirements analysis of the education analytics system. Therefore, in this paper, we studied the following research questions based on a case study:

\section{$R Q 1$ : What kind of approach is feasible for requirements analysis on an education analytics system?}

\section{$R Q 2:$ What were the lessons learned in the requirements analysis?}

The rest of the paper is organized as follows. In Section 2, we describe the related work on both the requirements analysis and education analytics. Then, in Section 3, we present the methodology and the case used, and in Section 4, we discuss the results. Finally, in Section 5 we have the overall discussion and conclusion about the work done.

\section{RELATED WORK}

In this section, we discuss the related work that our case is based on. First, the fundamentals of requirements analysis are covered, followed by the relevant viewpoints of education analytics.

\subsection{Requirements Analysis}

In plan-driven approaches, requirements analysis is an early phase of the system development life cycle, following the initiation and feasibility study [1]. Its goal is to produce comprehensive requirements documentation that serves as input for the design and building of a system [15], following a systematic process [16]. The requirements documentation should include the domain analysis, requirements and behavioral modeling [15]. These components are described in Table 1.

In change-driven approaches, requirements analysis is more scattered throughout the development life cycle, since minimal requirements analysis is done before each development iteration, the results are evaluated, and the next minimal round of requirements analysis is done before the following development iteration [5]. Meanwhile, changes to requirements are expected throughout development and minimal documentation is used, along with a dedicated person who has to be constantly available to give additional information as needed [17]. However, the domain analysis, requirements, and behavioral and data modeling will be done in change-driven approaches as well, as seen in Table 1.

Table 1. Components of requirements analysis in plan-driven and change-driven approaches.

\begin{tabular}{l|l|l}
\hline \hline Component & \multicolumn{1}{|c}{ Plan-driven approaches } & \multicolumn{1}{c}{ Change-driven approaches } \\
\hline Domain analysis & $\begin{array}{l}\text { Information, such as domain and business rule } \\
\text { dictionary, relevant processes and workflows } \\
\text { collected and documented, for example, as } \\
\text { text, tables or diagrams [15], [16]. }\end{array}$ & $\begin{array}{l}\text { Information collected by and available from } \\
\text { designated persons, such as product owner, as } \\
\text { necessary [5]. }\end{array}$ \\
\hline Requirements & $\begin{array}{l}\text { Requirements gathered, analyzed, and } \\
\text { documented, for example, as tables or show } \\
\text { cards [15], [16]. }\end{array}$ & $\begin{array}{l}\text { Requirements gathered, analyzed and } \\
\text { documented, for example, in product and sprint } \\
\text { backlogs [17]. }\end{array}$ \\
\hline $\begin{array}{l}\text { Behavioral and } \\
\text { data modeling }\end{array}$ & $\begin{array}{l}\text { Systems behavior meeting requirements and } \\
\text { necessary data modeled, using, for example, } \\
\text { user cases, mock-ups and diagrams or tables } \\
\text { [15], [16]. }\end{array}$ & $\begin{array}{l}\text { Systems behavior implemented in development } \\
\text { iterations, such as sprints, and evaluated in } \\
\text { reviews by designated person, for example, } \\
\text { product owner, and modified in following } \\
\text { development iterations as necessary [5], [17]. }\end{array}$ \\
\hline \hline
\end{tabular}




\subsection{Education Analytics}

Reliable analysis requires reliable data, and through digitalization, more data is available than ever before [18]. Digitalization is a phenomenon that affects all industries [19], and education is no exception. However, although digitalization has been studied in the education process, e.g., from an expert point of view [20], a comprehensive approach to developing education analytics systems is rare. In the existing literature, the term education analysis is rarely mentioned, and when it is, it normally refers to learner-focused learning analytics (as defined in [8], for example).

In the education domain, the most common target of analytics has been the actions and results of students [8]-[10], and the most common source of the data has been the learning environment that has been used to track the different activities and the overall progress [11], [12]. These can be considered as pedagogic outcomes and can be compared to pedagogic goals and objectives; for example, the need for the intervention of the teacher in individual students can be identified and the pedagogical behavior modified [9].

Most often, the analytics in education has been called learning analytics (such as in [8]-[13]), although it sometimes covers both learning (for example, learning results) and studying (for example, materials viewed or tasks completed). This difference has been recognized and combined with the additional identified areas, so that learning analytics has been divided into study, learning, biometric, environmental, and teaching analytics [13].

In addition, it seems that learning analytics is often separated from institutional analysis (see, e.g., [21]). The separation is somewhat problematic, since the main purpose of institutional analysis is to improve services, business practices, and processes [14], and learning analytics intends to enhance and improve students' success [21]. Distinguishing the two means that actions related to student learning would fall outside of the institutional processes and their development.

Therefore, we use the term education analytics in order to have a holistic picture, accounting for the relevant viewpoints and stakeholders in education. Our current view of education analytics (based on [14]) is presented in Fig. 1. It is a taxonomy of different analytics areas in the education domain, namely learning, study, teaching, guidance and process analytics, as well as several supporting areas, namely environmental, biometrics, and behavioral analytics, among others. Fig. 1 emphasizes areas of education analytics, since these are the ones that should be considered first in the education domain. Later, it is possible to assist these areas of analytics with their respective supporting areas.

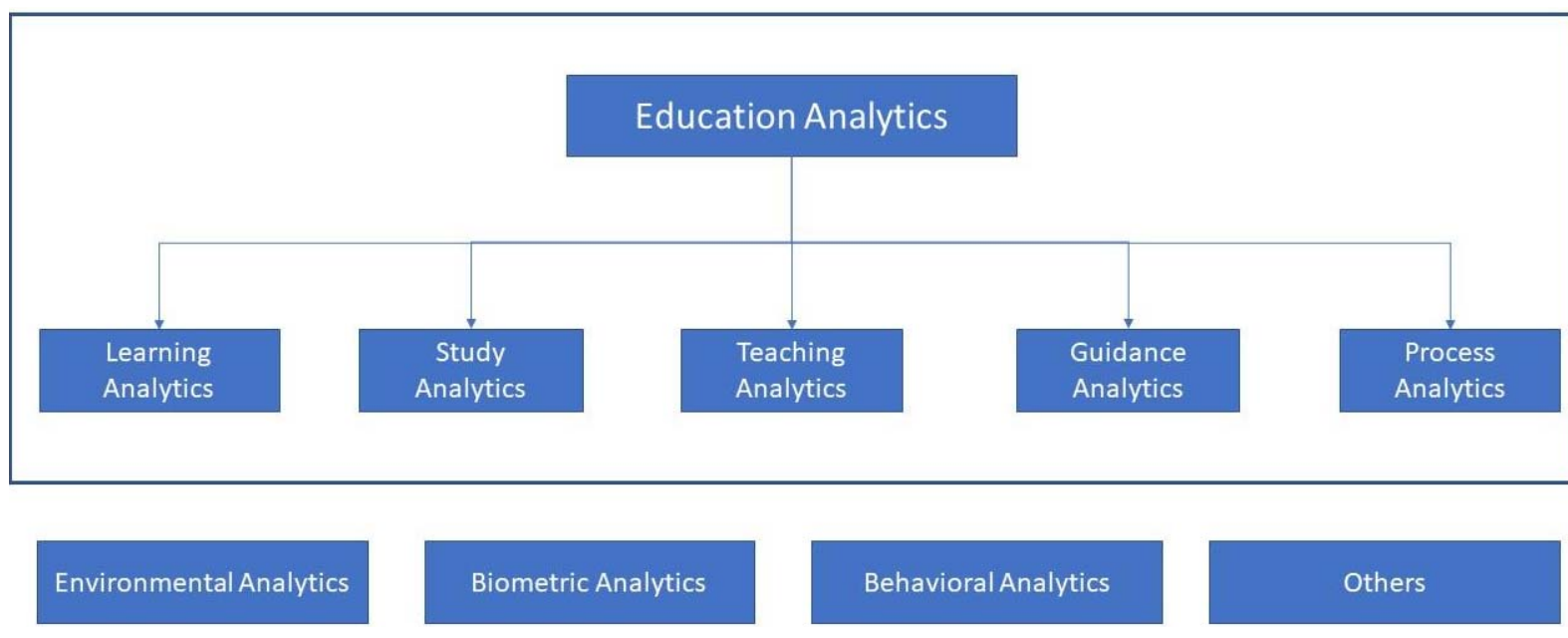

Figure 1. Education analytics.

In this view, learning analytics refers to the learning outcomes and gaps in learning, related to the learning goals. Study analytics refers to the progress of the student, such as time spent studying and completing tasks, as well as related interventions or needs of the teacher. Teaching analytics can be seen as having a similar idea for the teacher as study analytics has for the student, since, for example, it refers to how much time the teacher has spent on teaching, interventions, and developing teaching materials. Guidance analytics refers to information relevant in student guidance and counselling, such as overall progress of a group of students in their studies used by, for example, academic advisors. 
Finally, the process analysis refers to the institutional aspects in education, such as resource management, organizational (business) practices, and processes.

Among the supporting areas, environmental analytics refers to the physical environment, such as the classroom temperature or movements of the students. Biometrics analytics refers to sensor-gathered data from the individual, for example, the pulse or alertness of the student or teacher, while behavioral analytics refers to their observed behavior. There may also be other applicable supporting areas of analytics.

\section{METHODOLOGY AND CASE}

In this section, we discuss the methodology and the case this work is based on. First, the methodology related to the case study is discussed, followed by a description of the requirements analysis case itself.

\subsection{Methodology}

We applied the methodology of a case study as described, for example, in [22]. Of the possible sources of evidence [22], we used related documentation (e.g. background documents and e-mails), participant observations, and physical artefacts (the outcomes of the requirements analysis). The authors of this paper were all involved as experts in the case.

Since the approach to requirements analysis always has to be applied to a case [7], we used a constructive method [23] to develop a hybrid approach to the requirements analysis, based on the characteristics of the case. This means that we formed a synthesis based on the existing literature on plan-driven and change-driven approaches to requirements analysis, supported by our own prior experience in the field.

\subsection{Case}

Haaga-Helia UAS (University of Applied Sciences) participated in the APOA (learning analytics in the Universities of Applied Sciences) project [24], aiming to improve the use of analytics. As a part of the APOA project, an initial requirements analysis was done for an education analytics system at HaagaHelia UAS. This requirements analysis was to be based mainly on preliminary work done previously, since the needs of the different stakeholders had already been gathered in the APOA project and in other efforts. The previous work included, for example, interviews and workshops with different stakeholders as well as a prototype built in 2020 based on data available from the learning management system in use at Haaga Helia UAS.

The outcomes of the requirements analysis presented in this paper were to include at least use cases and cover the viewpoint of an advisor. Advisor refers here to both academic advisors who focus mainly on student guidance and counselling, but also to teachers who have guidance related tasks in addition to teaching, for example, who tutor one or more small groups of students in course of their studies. Additionally, the necessary data with reasoning of its necessity was to be defined as an outcome. This was based on the fact that data protection and privacy issues must be taken into careful consideration by EU-wide legislation, namely GDPR (General Data Protection Regulation) [25].

A group of four persons, including three lecturers from Haaga-Helia UAS and one external consultant, did the requirements analysis during the spring of 2021, supported by other persons from Haaga-Helia UAS as needed. It is worth noticing that there was a specific focus on the guidance given by teachers especially related to the students' personal study plans. This is because two of the lecturers in the group had acted in the tutoring role. The outcome, the requirements analysis documentation, broken down in its components (domain analysis, requirements, and behavioral and data modeling), is presented in Table 2.

Table 2. Outcome of the requirements analysis broken down to its components.

\begin{tabular}{l|l}
\hline \hline Component & \multicolumn{1}{c}{ Results } \\
\hline Domain analysis & $\begin{array}{l}\text { Goal, scope, target environment (including } 9 \text { identified, related, } \\
\text { ongoing development efforts) and stakeholder (3 groups) descriptions. }\end{array}$ \\
\hline Requirements & Requirements (24 analyzed and 67 other potential ones). \\
\hline $\begin{array}{l}\text { Behavioral and } \\
\text { data modeling }\end{array}$ & $\begin{array}{l}\text { Use cases (7), mock-ups (6), business rules (2), and a table containing } \\
\text { identified necessary data with reasoning of its necessity (97 entries). }\end{array}$ \\
\hline \hline
\end{tabular}


It is worth noting that the different components of the outcome are not separate, but instead, they are interrelated. The components and their relationships are illustrated in Fig. 2. As seen in the figure, the key relationship chain ranges from requirements to use cases, from use cases to mock-ups, and from mock-ups to the necessary data.

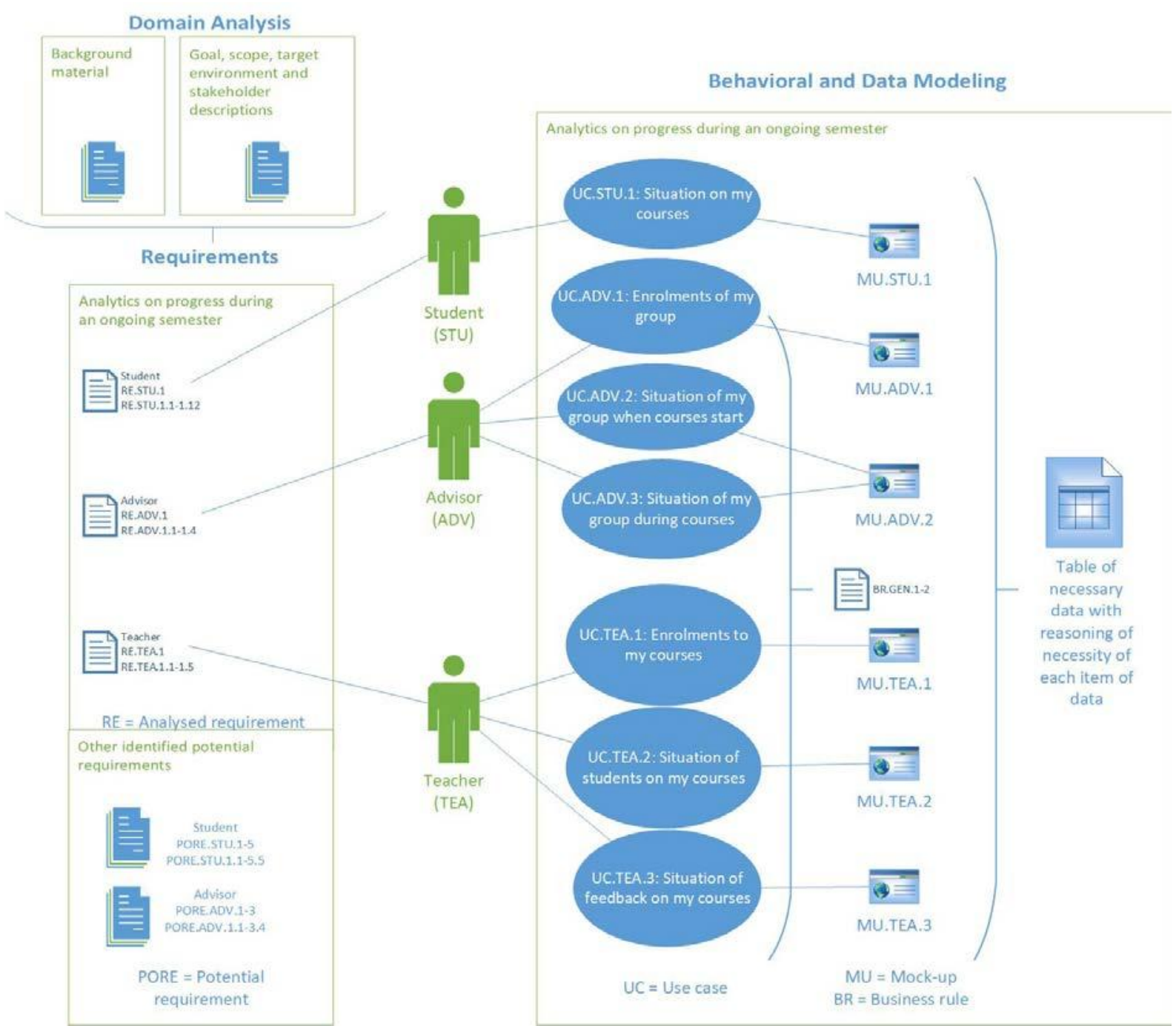

Figure 2. The outcome of the requirements analysis.

\section{RESULTS}

In this section, we discuss the results of our work, the reasoning behind using a hybrid model for the requirements analysis and present the hybrid model used. We also describe the lessons learned so far.

\subsection{Hybrid approach to requirements analysis}

In this case study, there were drivers in favor of both the plan-driven and change-driven approaches for the requirements analysis as discussed in Section 2.1. On the one hand, the definitions of the goal and outcome were very preliminary and flexible at the starting point of the work that was leaning towards the change-driven approach. Also, there was no existing education analytics system in place, meaning that it was thought the development could be done from scratch to support the change-driven approach. This was also supported by the fact that at an early phase of the work, we were able to identify nine other related development efforts that would have an impact on the target environment (such as related processes, workflows, or information systems) in the future. This meant that the target environment, for example, the workflows of students, advisors, and teachers, that the education analytics system would have to support, was in a state of transition during the requirements analysis. 
On the other hand, a concrete proposal for a feasible solution for implementation was required, even though the overall development was not yet in the design or build phase. This was steering towards a plandriven approach, where, in addition to stating the requirements, the behavior of a solution could be described with use cases and mock-ups, without doing any actual technical designing or building. This was also supported by the requirements for the outcome, stating that the necessary data with reasoning for its necessity should be included.

Based on these considerations, we decided to apply a hybrid approach of the plan-driven and changedriven approaches discussed in Section 2.1. Therefore, our answer to RQ1 (What kind of an approach is feasible for requirements analysis on an education analytics system?), in this case is a hybrid approach. A summary of the plan-driven and change-driven aspects by components of the hybrid approach is presented in Table 3.

Table 3. Plan-driven and change-driven aspects of the hybrid approach applied in the case.

\begin{tabular}{l|l|l}
\hline \hline Component & \multicolumn{1}{|c}{ Plan-driven aspects } & \multicolumn{1}{c}{ Change-driven aspects } \\
\hline Domain analysis & $\begin{array}{l}\text { Information on goal, scope, } \\
\text { and target environment } \\
\text { was collected and } \\
\text { documented as text and } \\
\text { diagram in the early phase } \\
\text { of the work (see, e.g. [15]). }\end{array}$ & $\begin{array}{l}\text { The goal was based on the minimum viable principle [26] and added } \\
\text { value [17]. } \\
\text { Due to the number of ongoing related development efforts (see 3.2 } \\
\text { and Table 2) affecting the target environment, a designated person } \\
\text { actively communicated with representatives from related efforts and } \\
\text { had the up-to-date information available (comparable to product } \\
\text { owner in [17]). }\end{array}$ \\
\hline Requirements & $\begin{array}{l}\text { Detailed requirements were } \\
\text { documented in a table wise } \\
\text { format, having the } \\
\text { reasoning, notes, and } \\
\text { priority as in [15]. }\end{array}$ & $\begin{array}{l}\text { The needs (higher level requirements) were documented as user } \\
\text { stories (see, e.g. [17]) and structured corresponding with the ideas } \\
\text { of features and epics (see, e.g. [27]). } \\
\text { Of all the (91) identified requirements (see Table 2), only the ones } \\
\text { (24) seen to belong in the MVP (minimum viable product, the first } \\
\text { release) were analyzed in detail (following the minimum viable } \\
\text { principle [26] and prioritized backlog [17]). After analysis, 6 of the } \\
\text { analyzed requirements were cut from the MVP, so the resulting MVP } \\
\text { consisted of 18 requirements. }\end{array}$ \\
\hline $\begin{array}{l}\text { Behavioral and } \\
\text { data modeling }\end{array}$ & $\begin{array}{l}\text { System behavior and } \\
\text { necessary data meeting } \\
\text { requirements were } \\
\text { modelled with use cases, } \\
\text { mock-ups and tables as in } \\
\text { [15]. }\end{array}$ & $\begin{array}{l}\text { The behavioral and data modeling was done based only on } \\
\text { requirements belonging to the MVP, following the minimum viable } \\
\text { principle [26] and the idea of added value [17]. } \\
\text { Mock-ups were done in development iterations, corresponding to } \\
\text { sprints [17], based on the use cases and reviewed after an iteration, } \\
\text { leading to updates in the use cases, mock-ups, and the necessary } \\
\text { data, until the mock-ups were accepted in the reviews. }\end{array}$ \\
\hline \hline
\end{tabular}

The goal of the requirements analysis was defined using ideas from the change-driven approach, namely the minimum viable principle [26] and added value [17]. This meant that the MVP (minimum viable product, the first release; see, e.g. [17]) was defined as the goal. The content of the MVP was defined to be analytics during an ongoing semester from the viewpoints of the key stakeholder groups of students, advisors, and teachers (see Fig. 2). This was based on the minimum viable principle, that a solution to have this content would be the minimum and add value, while being viable.

The content of the MVP also followed our view on education analytics as discussed in Section 2.3. The focus of the MVP was on study analytics, which was a natural starting point, since, for example, related data from the learning environment and study register was available without major changes in these systems. In addition, analytics on the progress of the students provided useful information for students, advisors, and teachers alike. The MVP also focused on teaching analytics, in the sense that it provided information to the teachers that could be used to focus teachers' efforts on the tasks that were most useful at certain points of time, during all the courses they were teaching.

As can be seen from Table 3, all the components of the requirements analysis (domain analysis, requirements, and behavioral and data modeling) had aspects of both the plan-driven and the changedriven approaches in the hybrid model applied in the case. Overall, it can be said that the baseline was plan-driven, since the actual design and building of the education analytics system was not in progress and would be done separately, based on the outcome of the requirements analysis. Also, there was also an ongoing technological feasibility study in progress that was to be concluded before moving to the actual design and build. However, change-driven aspects were applied in the requirements analysis as well to focus the work on the most important parts that were directly related to the MVP. In addition, the change- 
driven approach was used in the behavioral and data modeling to iterate these and to be able to get the details of a solution corresponding with the MVP, and meeting its requirements in full.

\subsection{Lessons learned}

Regarding RQ2 (What were the lessons learned in the requirements analysis?), we collected the lessons learned so far with their descriptions in Table 4. The lessons learned can be categorized into general, communication related, and substance related. The general lessons emphasized the application of the requirements analysis method based on the case at hand and the effect on the system development, including the requirements analysis, had on the workflows in the organization.

The lessons learned relating to communication focused on ownership and the need for clear vision and goals as well as the need for communication. Clear vision, goals and ownership was especially necessary from a communication perspective when the requirements analysis had connections, or was related to, other ongoing development efforts requiring coordination. Also, clear vision and goals are essential in order to ensure the quality of the results; without them, it is difficult to evaluate if the results match the goals and the vision. The need for communication referred to both communication between persons doing requirements analysis, as well as communication with the other relevant stakeholders.

Substance related lessons learned dealt with iteration and traceability. Since the requirements analysis was complex work, there was a need to iterate, regardless of the selected approach in the requirements analysis. Moreover, since iteration meant changes and the components of the requirements analysis were interrelated, there was a need to keep track of the relationships between the components in order to do impact analysis on changes.

Table 4. Lessons learned in the requirements analysis.

\begin{tabular}{|c|c|}
\hline Lesson learned & Description \\
\hline $\begin{array}{l}\text { Requirements } \\
\text { analysis approach } \\
\text { to be applied to the } \\
\text { case at hand. }\end{array}$ & $\begin{array}{l}\text { As seen from Table } 3 \text {, in our case, both plan-driven and change-driven aspects were useful. } \\
\text { However, this was based entirely on the characteristics of the case at hand, both from } \\
\text { organizational (target environment) and substance (education analytics system from scratch) } \\
\text { viewpoints. Therefore, in order to be able to do a feasible requirements analysis, the approach } \\
\text { must be applied based on the characteristics of the case. }\end{array}$ \\
\hline $\begin{array}{l}\text { System } \\
\text { development will } \\
\text { have an effect on } \\
\text { workflow. }\end{array}$ & $\begin{array}{l}\text { The core idea of system development is to enable or support business operations. In our case, } \\
\text { this was to support key stakeholders such as student, advisor and teacher in their everyday } \\
\text { activities, as described in Section 3.2. This meant that the system development would have an } \\
\text { effect on the workflow. Because of this, it was essential to identify related workflows and } \\
\text { processes and their status (such as stable or under development), in order to base the } \\
\text { requirements analysis on the up-to-date situation. }\end{array}$ \\
\hline $\begin{array}{l}\text { Ownership is } \\
\text { essential. }\end{array}$ & $\begin{array}{l}\text { It is typical, especially in large organizations, that there are multiple, related development efforts } \\
\text { active at the same time. This was true in our case as seen in Section } 3.2 \text { and Table } 2 \text {. This } \\
\text { emphasized a clear ownership of each of the development efforts, so that it was possible to align } \\
\text { and coordinate the work without unnecessary overlaps and was effective as a whole. }\end{array}$ \\
\hline $\begin{array}{l}\text { The need for clear } \\
\text { vision and goals }\end{array}$ & $\begin{array}{l}\text { The overall vision and goals related to the target of the requirements analysis and for the } \\
\text { requirements are essential to be defined early and clearly. Since they are often, such as in our } \\
\text { case (see Section 3.2), coming from the organizational level, there should be a relevant } \\
\text { stakeholder having the ownership (see above) and defining the vision and goals for the } \\
\text { requirements analysis from that level. This relates also to quality assurance aspects of the } \\
\text { requirements analysis, since the stakeholder in question should be able to determine if the results } \\
\text { of the requirements analysis are acceptable based on the vision and the goals. }\end{array}$ \\
\hline $\begin{array}{l}\text { The need to } \\
\text { communicate. }\end{array}$ & $\begin{array}{l}\text { Requirements analysis is a non-trivial task, as illustrated in our case. For example, the complexity } \\
\text { and internal relationships within the outcome can be seen in Fig. } 2 \text {. To maintain a shared view of } \\
\text { the requirements analysis, communication was vital, both between the persons doing the } \\
\text { requirements analysis, as well as with the other stakeholders. The communication with the other } \\
\text { relevant stakeholders is related to the ownership mentioned above. }\end{array}$ \\
\hline The need to iterate. & $\begin{array}{l}\text { Due to the complexity, the components of the requirements analysis (see Table 1) needed to be } \\
\text { iterated, regardless of whether a plan-driven, change-driven or, as in our case (see Section } 4.1 \\
\text { and Table 3), a hybrid approach was used. This was especially evident in the behavioral and data } \\
\text { modeling as discussed in Section } 4.1 \text {. An important aspect of iterations is to iterate early and } \\
\text { often with the stakeholders in order to gain further input for the requirements analysis. }\end{array}$ \\
\hline $\begin{array}{l}\text { The need to track } \\
\text { traceability. }\end{array}$ & $\begin{array}{l}\text { Since many relationships existed between the components of the requirements analysis in our } \\
\text { case, as illustrated in Fig. } 2 \text {, the iterations mentioned before, often have a chain effect requiring } \\
\text { changes to multiple components. This is why it was necessary to keep track of the traceability of } \\
\text { the relationships between the components, enabling the impact analysis of each change. }\end{array}$ \\
\hline
\end{tabular}




\section{CONCLUSIONS}

Requirements analysis is a non-trivial and complex task. Although plan-driven and change-driven approaches, and other applicable methods are well known, they must always be selected and applied based on the case at hand. This is illustrated by the case study in this paper, where the requirements analysis of an education analytics system for a higher education institution was done.

The case had drivers towards both plan-driven and change-driven approaches on requirements analysis. These drivers were based on both organizational viewpoints, such as data protection, the privacy legislation to follow, and substance related viewpoints, such as the lack of an existing education analytics system and the relative novelty of educational analytics. Although the case was an individual example, we suggest that our findings are applicable to similar cases.

It is worth noticing that in the case, there was a specific focus on the guidance given by teachers especially related to the students' personal study plans. This was due to the fact that two of the four members in the group doing the requirements analysis had acted in a tutoring role. This eased the work process, since the guidance domain was familiar from that viewpoint within the group. This has had an effect on the substance related choices made during the requirements analysis. Also, the two group members had a dual role of both domain expert and requirements analyst meaning that they have had more influence in the result than, for example, the external consultant.

In this case, we successfully applied a hybrid approach to requirements analysis. The approach had a plan-driven baseline, since the actual design and building of the education analytics system was not in progress and would be done separately, based on the outcome of the requirements analysis. However, change-driven aspects were also applied to focus the work on the most important aspects having the highest priority. In addition, the change-driven approach was used in the behavioral and data modeling to iterate these and to be able to achieve a feasible solution.

The lessons learned from the case can be categorized into general, communication related, and substance related. The general lessons learned emphasized the application of the requirements analysis method, based on the case at hand, and the effect that the system development, including the requirements analysis, had on the workflows in the organization. The communication related lessons learned focused on the ownership and the need for communication, while the substance related lessons learned dealt with iteration and traceability.

Overall, one of the key observations was that in order to do an accurate requirements analysis, a comprehensive systems analysis was needed. This included, for example, identifying and involving the key stakeholders early on in the process, in order to build a shared knowledge of the existing as-is situation and a collective vision as well as understanding of the overall goals. This enables the identification of the related processes and workflows, as well as a balanced analysis of the needs and requirements that had to be fulfilled to reach the overall goal. An important aspect is also to check and define the ownership and the mandate of the requirements analysis early.

The requirements analysis done in the case would probably still have benefitted from at least from a more formal concept analysis in the early phases in order to ease, for example, the communication within the group working on requirements analysis as well as with the different stakeholders. In a similar vein, in the case an in general, the multiple roles of the persons doing the requirements analysis is worth noticing and keeping in mind. It is necessary to incorporate, for example, the roles of the product owner, requirements analyst, domain expert and requirements analysis methodology expert in a balanced manner within the group working on the requirements analysis.

In relation to education analytics, in order to be feasible, the development of learning, study, teaching and guidance analytics should be a part of the overall development of learning, study and teaching processes. Thus, the development of the related analytics should not be an isolated task, but an integral part of the process development in education. This way, also any requirements analysis done within this domain would need to incorporate both of these aspects.

\section{ACKNOWLEDGMENTS}

This work has been funded by the APOA project [24]. 


\section{REFERENCES}

[1] P. Bojic, A. Greasley, and S. Hickie, Business information systems : technology, development and management for the modern business, Sixth edit. Pearson, 2019.

[2] Business Technology Forum, "Business Technology Standard," 2021. https://www.managebt.org/.

[3] R. Kauppinen, A. Lagstedt, and J. P. Lindstedt, Expert-oriented digitalization of university processes, vol. 11984 LNCS. 2020.

[4] N. B. Moe, A. Aurum, and T. Dybå, "Challenges of shared decision-making: A multiple case study of agile software development," Inf. Softw. Technol., vol. 54, no. 8, pp. 853-865, Aug. 2012, doi: 10.1016/j.infsof.2011.11.006

[5] I. Inayat, S. S. Salim, S. Marczak, M. Daneva, and S. Shamshirband, "A systematic literature review on agile requirements engineering practices and challenges," Comput. Human Behav., vol. 51, pp. 915-929, Oct. 2015, doi: 10.1016/j.chb.2014.10.046

[6] G. Theocharis, M. Kuhrmann, J. Münch, and P. Diebold, "Is water-scrum-fall reality? On the use of agile and traditional development practices," in International Conference on Product-Focused Software Process Improvement, 2015, vol. 9459, pp. 149-166, doi: 10.1007/978-3-319-26844-6_11

[7] A. Lagstedt and T. Dahlberg, "A Contingency Theory Motivated Framework to Select Information System Development Methods," in Pacific Asia Conference on Information Systems, Jun. 2018, pp. $1-14$.

[8] R. Ferguson, "Learning analytics: Drivers, developments and challenges," Int. J. Technol. Enhanc. Learn., vol. 4, no. 5-6, pp. 304-317, 2012, doi: 10.1504/IJTEL.2012.051816

[9] W. Greller and H. Drachsler, "Translating learning into numbers: A generic framework for learning analytics," Educ. Technol. Soc., vol. 15, no. 3, pp. 42-57, 2012.

[10] N. Sclater, A. Peasgood, and J. Mullan, "Learning Analytics in Higher Education. A review of UK and international practice," Jisc: Bristol, 2016.

[11] M. A. Chatti, A. L. Dyckhoff, U. Schroeder, and H. Thüs, "A reference model for learning analytics," Int. J. Technol. Enhanc. Learn., vol. 4, no. 5-6, pp. 318-331, 2012, doi: 10.1504/IJTEL.2012.051815

[12] G. Siemens, "Learning Analytics: The Emergence of a Discipline," Am. Behav. Sci., vol. 57, no. 10, pp. 1380-1400, 2013, doi: 10.1177/0002764213498851

[13] S. Suhonen, "Oppimisanalytiikka (Learning Analytics)." Tampere University of Applied Sciences, 2018, [Online]. Available: https://www.youtube.com/watch?v=9MEavXkVOOA

[14] R. Kauppinen and A. Lagstedt, "TOWARDS MINIMUM VIABLE EDUCATION ANALYTICS," Mar. 2021, pp. 5610-5616, doi: 10.21125/inted.2021.1130

[15] N. Ashrafi and H. Ashrafi, Object-Oriented Systems Analysis and Design. Pearson Higher Education, 2008.

[16] S. Robertson and J. Robertson, Mastering the Requirments Process, 3rd ed. Addison-Wesley, 2013.

[17] ScrumGuides.org, "Scrum Guide," 2020. https://scrumguides.org/scrum-guide.html

[18] R. Kauppinen, A. Lagstedt, and J. Lindstedt, "Digitalizing Teaching Processes - How to Create Usable Data with Minimal Effort," Eur. J. High. Educ. IT, vol. 1, 2020.

[19] M. Borg, J. Wernberg, T. Olsson, U. Franke, and M. Andersson, "Illuminating a Blind Spot in Digitalization - Software Development in Sweden's Private and Public Sector," 2020.

[20] A. Lagstedt, J. P. Lindstedt, and R. Kauppinen, "An outcome of expert-oriented digitalization of university processes," Educ. Inf. Technol., vol. 25, no. 6, pp. 5853-5871, Nov. 2020, doi: 10.1007/s10639-020-10252-x

[21] P. Arroway, G. Morgan, M. O'Keefe, and R. Yanosky, "Learning Analytics in Higher Education," Loiseville, 2016.

[22] R. K. Yin, Case Study Research: Design and Methods, 5th ed. Sage Publications, 2014. 
[23] E. Kasanen and K. Lukka, "The constructive approach in management accounting research," J. Manag. Account. Res., vol. 5, no. 5, pp. 243-264, 1993.

[24] The APOA project, "Learning analytics in the Universities of Applied Sciences," 2021. https://apoa.tamk.fi/in-english/

[25] General Data Protection Regulation (2016/679). 2016.

[26] S. Blank, "Why the lean start-up changes everything," Harv. Bus. Rev., vol. 91, no. 5, 2013.

[27] H. R. Herdika and E. K. Budiardjo, "Variability and Commonality Requirement Specification on Agile Software Development: Scrum, XP, Lean, and Kanban," 2020 3rd Int. Conf. Comput. Informatics Eng. IC2IE 2020, pp. 323-329, 2020, doi: 10.1109/IC2IE50715.2020.9274564 